\title{
REFLEXÕES SOBRE O PROCESSO DE AVALIAR DOCENTE CONTRIBUINDO COM SUA FORMAÇÃO
}

\author{
Ana Maria Castanheira ${ }^{1}$ \\ Mary Rosane CERONI ${ }^{2}$ \\ Recebido em: 05/07/07 \\ Avaliado em: 20/09/07
}

1 Professora Titular do CCH/MACKENZIE e Escola de Engenharia/MACKENZIE desde fev 1974: Coordenadora da Comissão Própria de Avaliação da UPM desde 2001. Professora e Pesquisadora Integrante do FOPEP - Fórum Permanente de Educação e Pesquisa/ Mackenzie, desde 2003;, Diretora da Faculdade de Ciências Exatas e Experimentais da UPM (1991-2001).Participa do Grupo de Pesquisa : Ensino Superior: Projetos Didáticos Pedagógicos e Docência desde 2000 e é Lider do Grupo de Pesquisa: Formação do Docente do Ensino Superior frente às novas Prática Avaliativas e de Gestão Comtemporânea desde 2007. Participa como lider do Projeto de Extensão Evasão Mínima como consequiência de uma Motivação Maior" desde 2007.

Universidade Pesbiteriana Mackenzie- Rua da Consolação 896- $8^{\circ}$ andar - Consolação-01302-907 e-mail castanheira@mackenzie.com.br

2 Professora Adjunto no CCH / MACKENZIE desde fev 1993; Professora e Pesquisadora Integrante do Grupo Didática do Ensino Superior vinculado ao FOPEP - Fórum Permanente de Educação e Pesquisa/ Mackenzie, desde 2003; Professora Responsável pelo FOPEP desde 2007. Professora e Coordenadora do Centro de Formação de Professores/ Módulos Licenciatura (fev 1993 -jan 2001; e a partir de fev 2007); Professora no Curso Formação Docente para o Ensino Superior : Gestão Educacional na Contemporaneidade /Pós-Graduação- Universidade Presbiteriana Mackenzie. Professora na Pós-Graduação da FMU desde 2001( Docência no Ensino Superior/ MBA Gestão Educacional), e Pesquisadora no Grupo de Pesquisa Educação e Inclusão Social na linha temática Formacão de Frofessores de ago 2004a dez 2005/ FMU. Líder do Grupo de Pesquisa Educação, Gestão e Sociedade / Mackenzie, desde 2006.

Universidade Pesbiteriana Mackenzie- Rua da Consolação 896- prédio 12 - Consolação-01302-907 e-mail maryrosane@mackenzie.com.br

Resumo: Baseando-se na importância dos processos de avaliação educacionais previstos e enfatizados pelo SINAES (Sistema de Avaliação da Educação Superior) e levando em conta novas abordagens sobre a formação do docente do ensino superior desenvolve-se a presente discussão sobre a inserção de práticas avaliativas. Busca-se identificar processos de avaliação que sejam relevantes e que tenham um papel eficiente para provocar mudanças frente aos conflitos e a complexidade do processo de ensino. O estudo fundamenta-se na reflexão sobre o que é importante na implantação de processos de avaliação dos docentes e na discussão de uma metodologia apropriada que contribua para a formação do educador, para a obtenção de dados confiáveis e sua análise visando à tomada correta de decisão. A questão central é o que é esperado professor frente às novas concepções de avaliação e ensino.

Palavras chave: Qualidade, Avaliação, Formação de Docentes, Ensino.

Contributions of the Teacher Evaluation Process to Continued Education.

Abstract: The present text is a discussion concerning the introduction of evaluation practices, based on the importance of the educational evaluation processes described and emphasized by SINAES (National Higher Education Evaluation System) and taking into account new approaches on education of professors. We will try to identify evaluation processes that are relevant and that have an effective role to provoke changes in view of the conflicts and the complexity of the teaching process. The study is based on the reflection about what is important in the implementation of the teacher evaluation process and in the discussion about an appropriate methodology that can contribute to the preparation of educators, to the achievement of reliable data and its analysis, and to decision making. The core question is what is expected of the teachers in light of the new conceptions of evaluation and teaching.

Key words: Quality; Evaluation; Teacher Education; Teacher. 


\section{Introdução}

As IES (Instituições de Ensino Superior) acompanham as orientações e recomendações sobre o desenvolvimento dos processos avaliativos sugeridos pelo SINAES (Sistema de Avaliação da Educação Superior) e buscam adaptar-se para que o projeto de Avaliação Institucional se torne cada vez mais completo. Como conseqüência, planeja-se e implantam-se mudanças no cotidiano acadêmico e administrativo tendo como prioridade, a efetiva participação na realidade brasileira priorizando os reais interesses da sociedade.

A Avaliação Institucional deve organizar os diversos instrumentos avaliativos de acordo com o principio da integração. O objetivo é desenvolver uma avaliação constituída basicamente no processo de auto-avaliação visando principalmente o auto-conhecimento institucional.

Os processos avaliativos precisam construir a globalidade e a integração entre o sujeito e o objeto. A redução do fenômeno complexo e multidimensional da avaliação a um só ou poucos aspectos, sem articulação, traz o risco de resumir o processo a um desses instrumentos dedicados a medir e comparar, o que pode comprometer os resultados de desfigurar objetivos, portanto o aspecto da globalidade deve ser enfatizado sob pena de perder-se o entendimento multidimensional.

A avaliação global da eficiência e da eficácia das atividades de Ensino-Pesquisa e Extensão vem sendo feita através do exame e da análise de dados contendo resultados tanto dos aspectos operacionais como acadêmicos dos diversos Cursos, Unidades, Programas da Instituição. Esses componentes incluem a parte administrativa, as relações com a comunidade em que a Instituição está inserida e até o clima institucional.

De acordo com a Comissão Nacional da Educação Superior CONAES (2005), a avaliação qualitativa desenvolve-se a partir de indicadores que objetivam compreender e analisar a qualidade dos processos e práticas vivenciadas, em uma perspectiva dinâmica e auto-referenciada. Para esta Comissão, esses indicadores se identificam com os propostos no Roteiro de Auto-Avaliação, explicitando elementos que, para além da mera presença de determinado atributo, denotam condições, relações, interações, aplicações e dinâmicas resultantes do projeto da instituição e da perspectiva que esta assume para assegurar a formação profissional e cidadã e o desenvolvimento científico-tecnológico. Para a composição do conceito final da avaliação externa de uma IES, dez dimensões são necessárias, 
REFLEXÕES SOBRE O PROCESSO DE AVALIAR DOCENTE CONTRIBUINDO COM SUA FORMAÇÃO

considerando seu distinto significado no processo de construção da qualidade. A CONAES (2005, p. 13) afirma: "Cada indicador será pontuado segundo uma referência pré-estabelecida, utilizada para reduzir a subjetividade do avaliador e estabelecer padrões de avaliação. Não obstante, o avaliador também poderá apresentar uma apreciação qualitativa em relação a cada dimensão e à instituição como um todo."

A CONAES (2005, p. 14) ao apresentar a dimensão Perspectiva científica e pedagógica formadora: políticas, normas e estímulos para o ensino, a pesquisa e a extensão, enfatiza:

- Relação das atividades de ensino com as demandas locais, regionais, nacionais e/ou internacionais, com os Projetos Pedagógicos dos Cursos e suas propostas curriculares, formuladas dentro de padrões de qualidade científica e pedagógica objetivando qualificação profissional e a formação cidadã;

- Apoio aos estudantes de graduação e pós-graduação por meio de bolsas de monitoria, bolsas de iniciação científica, tutorias, ofertas de estudos compensatórios gratuitos, bolsas trabalho entre outros, com vistas à qualificação da sua formação;

- Articulação e proposição de uma política de ensino de graduação e/ ou pós-graduação que estimule inovações e a melhoria do ensino, incluindo a qualificação pedagógica dos docentes (atuação de setor de apoio pedagógico; espaços de partilha de experiências; ambientes de estudo para professores e estudantes com infra-estrutura de apoio; recursos para projetos de ensino inovadores; carga horária para reuniões e preparação de atividades de ensino; apoio à participação em cursos de pós-graduação e em eventos acadêmicos entre outros);

- Relação dos cursos de Mestrado, Doutorado, de Especialização e de Educação Continuada com o ensino de graduação e de acordo com a produção científica da IES;

- Desenvolvimento de projetos estimulando as inovações curriculares e metodológicas.

Observa-se que todas as ações pertinentes aos processos avaliativos desta dimensão visam caminhos que levam a uma maior qualidade. A noção de qualidade está e esteve sempre presente na busca da eficiência e eficácia de todos os processos educacionais e administrativos. 
Todas as ações pertinentes aos processos avaliativos visam caminhos que levam a uma maior qualidade. A noção de qualidade está e esteve sempre presente em na busca a eficiência de todos os processos educacionais e administrativos.

\section{Avaliação Docente}

A avaliação educacional na contemporaneidade abrange a aprendizagem dos discentes em sala de aula, o sistema universitário e as universidades. Ressalta-se que a avaliação do sistema universitário, por intermédio da avaliação externa e/ou interna das instituições, apresenta desdobramento em duas modalidades: a avaliação institucional (administrativa ou organizacional) e a avaliação acadêmica ou científica (produção de informações sobre os resultados da aprendizagem em função do acompanhamento e da revisão das políticas educacionais, com a finalidade de formular indicadores de qualidade dos resultados do ensino.

Neste contexto, evidencia-se a necessidade dos educadores, considerarem a avaliação importante meio diagnóstico de seu trabalho, bem como a elaboração de instrumentos mais diretos de aferição da qualidade de ensino e da aprendizagem do aluno que se quer formar.

Verifica-se que, as ações da universidade no campo da avaliação educacional, orientadas para a formação continuada dos professores universitários no contexto do trabalho, voltado ao desenvolvimento de competência interativa entre si e com os discentes; de capacidades e habilidades de liderança - entendida como a capacidade de influenciar, incentivar, integrar e organizar pessoas e grupos, com o firme propósito de trabalharem para a consecução de objetivos (LIBÂNEO, 2003).

Luckesi (2002),por sua vez, afirma que a avaliação é um dos aspectos mais problemáticos do processo de ensino, porque normalmente utilizada apenas com o sentido de verificação, não apresenta efeitos na dinâmica da ação pedagógica conduzida pelo docente. O autor faz suas ponderações, alertando para o real significado da avaliação:

A avaliação atravessa o ato de planejar e de executar;por isso contribui em todo o percurso da ação planificada. [...] A avaliação se faz presente não só na identificação da perspectiva político-social, como também na seleção dos meios alternativos e na execução do projeto, tendo em vista a sua construção. [...] É uma ferramenta necessária ao 
REFLEXÕES SOBRE O PROCESSO DE AVALIAR DOCENTE CONTRIBUINDO COM SUA FORMAÇÃO

ser humano de construção dos resultados que planificou produzir [...] Ela faz parte de seu modo (do professor) de agir, e por isso, é necessário que seja usada da melhor forma possível. [...] Defino a avaliação da aprendizagem como um ato amoroso, no sentido de que a avaliação, por si, é um ato acolhedor, integrativo, inclusivo.

Ao se pensar na avaliação da aprendizagem em um projeto educativo, Hoffmann (2003) assim se expressa:

$\mathrm{O}$ ato de avaliar se faz presente em todos os momentos da vida humana [...] ele também está presente em todos momentos vividos em sala de aula. [ ...] A avaliação efetiva vai ocorrer durante o processo, nas relações dinâmicas de sala de aula, que orientam as tomadas de decisões freqüentes, relacionadas ao tratamento do conteúdo e à melhor forma de compreensão e produção do conhecimento pelo aluno. [...] É nas relações cotidianas entre professor e aluno que vai se dar a aprendizagem.

Segundo Hoffmann (2003) Dessa interação vão surgir condições mais efetivas para que professores e alunos possam ser capazes de se avaliar, de avaliarem o conteúdo em questão e de tomarem decisões quanto ao prosseguimento do processo do ensino e da aprendizagem.

O papel do docente é fundamental na implantação de qualquer processo de mudança relativo ao sistema de ensino, conforme Silva (2004). Sem a conscientização, adesão e participação dos professores, qualquer tentativa de diferentes abordagens fracassará. Convém ressaltar que, além da figura do professor é importante também, a integração e participação de todos os envolvidos no processo.

O foco da qualidade de ensino e do sucesso da aprendizagem está diretamente ligado à atuação do professor em sala de aula e em suas atividades acadêmicas. Assim, existe a necessidade da fixação de metas para o sucesso da empreitada.

Acompanham-se na atualidade, as mudanças que vêm ocorrendo nos campos das diversas ciências, inclusive da educação, que levam à necessidade de se repensar a formação atualmente oferecida aos professores universitários. Para Moraes (1997), tem-se hoje configurado um processo de mudanças no contexto global no qual se inserem as instituições de ensino superior, mudanças estas relacionadas, em especial, ao avanço científico- 
tecnológico, a alterações na organização do trabalho, à sociedade de informação, aos processos de globalização da economia e a alterações na relação dos sujeitos com o conhecimento.

Neste contexto, o processo de avaliação em si, sem consequiências, gera falta de estímulo, os professores sempre devem ter a oportunidade de se capacitar e acompanhar o desenvolvimento das fronteiras tecnológicas. Para Castanheira (2005) atualmente, com a globalização, têm-se um acadêmico diferenciado, que não aceita aprender por aprender, e por esta razão um desenvolvimento de novas metodologias de ensino, pois as técnicas de aprendizado tiveram que se adaptar a essa realidade, para atender necessidades antes desconhecidas.

Não há dúvidas que a Universidade deva realizar avaliações periódicas de seus docentes, mas há de se considerar a habilidade do avaliador que deve respeitar as características e o perfil de cada área. Quando as avaliações não são feitas por especialistas competentes e éticos, os danos causados podem ser de longa duração. Para a discussão desses aspectos e dos resultados do processo avaliativo, implantou-se em 2003 o Fórum Permanente de Educação e Pesquisa que tem como objetivo desenvolver a formação continuada de professores por meio de pesquisa e produção docente e organização de atividades que permitam o desenvolvimento da atualização pedagógica prática docente para professores da Universidade.

Um dos componentes do processo de avaliação institucional é o levantamento da opinião discente sobre as atividades didático-pedagógicas de seus professores. Tarefa complexa, pois ao professor cabe, por vezes, não satisfazer seus alunos e suas expectativas imediatistas. Segundo Machado(1997).

Ao educador compete, muitas vezes, a coerção legítima, que gera a insatisfação imediata na busca de resultados ou valores que não poderão ser apreciados senão, talvez, em um futuro remoto. Faz parte do papel do professor assumir responsabilidades diante da realidade que vivencia, ainda que isso acarrete o risco de terem-se clientes insatisfeitos em razão de eventuais interesses aparentemente contrariados. Um professor pode e deve correr riscos como esse. Tanto do ponto de vista conceitual quanto do ponto de vista prático, a do cidadão não pode, portanto, em nenhuma circunstância, ser reduzida à mera satisfação do cliente. 
REFLEXÕES SOBRE O PROCESSO DE AVALIAR DOCENTE CONTRIBUINDO COM SUA FORMAÇÃO

Para que se possa implantar um processo de avaliação docente com sucesso é preciso realizar uma sensibilização de todos os envolvidos. Deve estar claro para o corpo docente o objetivo da avaliação é a melhoria e não a punição, e, para os alunos a importância de sua opinião (que deve ser a mais justa possível e não um ajuste de contas), para que possam contribuir para a melhoria de sua formação.

Para Leal (2004), o papel do docente é fundamental na implantação de qualquer processo de mudança relativo ao sistema de ensino. Sem a conscientização, adesão e participação dos professores, qualquer tentativa de diferentes abordagens fracassará. Convém ressaltar que, além da figura do professor é importante também, a integração e participação de todos os envolvidos no processo.

O foco da qualidade de ensino e do sucesso da aprendizagem está diretamente ligado à atuação do professor em sala de aula e em suas atividades acadêmicas. Assim, existe a necessidade da fixação de metas para o sucesso da empreitada.

Os pressupostos de estratégias de sala de aula devem ser frutos de muita reflexão, pois pode nem sempre uma situação de ensino necessariamente significa que os processos de aprendizagem realmente ocorreram. Para Anastasiou (2003), deve ser provocada uma situação que estabeleça parceria entre professor e aluno - condição fundamental para o enfrentamento do conhecimento, necessária à formação do aluno durante o cursar da graduação; a aula entendida como momento e espaço privilegiado de encontro e de ações, deve ser construída na ação conjunta de professor e aluno.

O relacionamento entre os professores e alunos deve ser estreitado enquanto parceria gerando uma cumplicidade de ações objetivando um maior aproveitamento. Os professores precisam acompanhar o desenvolvimento das fronteiras tecnológicas para contribuir e interagir com o aluno. Segundo Castanheira (2005), atualmente, com a globalização, têm-se um acadêmico diferenciado, que não aceita aprender por aprender. Um acadêmico que exige novas metodologias e técnicas de aprendizado para atender às necessidades de uma nova realidade que se impõe.

\section{Procedimentos}

Para operacionalizar o processo de avaliação do docente pelos alunos a Comissão Própria de Avaliação organiza um calendário de tal forma que 
os alunos de todos os cursos participem. Membros da CPA (Comissão Própria de Avaliação) estão presentes nas salas de aula durante o processo com a tarefa de realizar uma sensibilização dos discentes quanto a importância da participação de todos. Os alunos recebem as questões e as respondem, sem a necessidade de se identificar, em seguida a tabulação é realizada com o auxílio de leitura óptica.

Cerca de 29000 alunos dos cursos de graduação respondem e participam do processo, avaliando em torno de 1300 professores. O questionário é composto por 17 questões versando sobre o desempenho docente, a estrutura física e a auto-avaliação discente. Os acadêmicos atribuíram notas de 1 (ruim) a 5 (ótimo) para cada questão do questionário. O processo é repetido anualmente (desde 2001) criando a possibilidade de comparações entre as Unidades e entre as disciplinas que um mesmo professor leciona.

As dezessete questões são comuns e todas as Unidades se utilizam desses parâmetros, no entanto, se um curso achar apropriado a inclusão de alguma questão específica além das comuns, basta solicitar a CPA que atenderá ao pedido incluindo o que for necessário.

Tabela 1-Resultados (médias) obtidos nos cursos de Engenharia, Comunicação e Artes e Arquitetura em 2002/2003.

\begin{tabular}{|l|l|l|}
\hline Unidade & $\mathbf{2 0 0 2}$ & $\mathbf{2 0 0 3}$ \\
\hline Engenharia & & 3,71 \\
\hline Arquitetura & 3,48 & 3,53 \\
\hline Comunicação e Artes & 3,47 & 3,57 \\
\hline
\end{tabular}

Cada professor tem acesso a sua própria avaliação por meio de uma senha na intranet, sendo os resultados são discutidos pelos docentes em reuniões individuais com as coordenações. Não foi cogitado ranking de atuação dos professores, pois o objetivo é a discussão e a análise dos resultados objetivando a melhoria do desempenho individual de cada professor.

A Reitoria da Universidade, a direção das Unidades e as coordenadorias dos cursos possuem acesso a todas as avaliações docentes. As análises são criteriosas e levam em conta diversos fatores como a média da Unidade e o perfil do aluno.

Como o processo de avaliação docente vem se realizando sem incidentes os professores estão mais confiantes e menos temerosos. Os resultados totais da Universidade são bons. Pode-se afirmar que o corpo docente, no geral, além de ser bem preparado profissional e academicamente, é 
REFLEXÕES SOBRE O PROCESSO DE AVALIAR

DOCENTE CONTRIBUINDO COM SUA FORMAÇÃO

considerado muito bom pelos alunos, levando em consideração o desempenho em sala de aula..

No entanto $18 \%$ dos professores que foram avaliados obtiveram média inferior ao valor considerados crítico. A intenção é implantar ações que visam à melhoria do ensino/ aprendizagem, utilizando os resultados obtidos e pontuando as maiores fragilidades. Volta-se então a atenção para professores mal avaliados. Surgem então as questões: O que fazer? Que procedimentos adotar? Por que as avaliações desses professores foram sofríveis?

\section{FOPEPE (Fórum Permanente de Educação, Pesquisa e Extensão)}

Já não há dúvidas que a Universidade deva realizar avaliações periódicas de seus docentes, mas é preciso também respeitar as características e o perfil de cada área. Quando as avaliações não são feitas por especialistas competentes e éticos, os danos causados podem ser de longa duração.

Considerando a importância do educador e levando em conta a preocupação de encontrar um caminho que contribua efetivamente para a melhoria, não só de professores mal avaliados pelos seus alunos, mas com a qualidade e formação do professor no geral implanta-se o Fórum Permanente de Educação e Pesquisa e Extensão (FOPEPE) que seria um espaço para discussão e reflexão sobre a tarefa de ser educador. Ressalta-se aqui que na analise dos dados da avaliação docente e independente da média obtida por cada professor, $91 \%$ dos alunos considera que seus professores conhecem muito bem o conteúdo que desenvolve. No entanto, eles não têm a didática necessária (39\%) e não se utilizam de metodologias outras que não a aula expositiva (36\%).

Dentre os objetivos do FOPEPE, destacam-se os seguintes:

- Refletir acerca do papel de educador do docente do ensino superior e sobre sua ação educativa na formação de profissionais comprometidos com a construção do conhecimento e com as necessidades atuais da sociedade;

- Fomentar a discussão, a avaliação e a revisão das práticas docentes desenvolvidas no ensino superior;

- Incentivar a pesquisa e a divulgação dos resultados e experiências no campo da ação docente no ensino superior; 
- Atender às demandas, referentes à formação continuada de seus professores;

- Propor às atividades que contribuam para o desenvolvimento dos diferentes agentes educacionais;

- Propor Cursos, Seminários, Grupos de Estudos, Debates, Palestras e demais atividades;

- Propor a criação de grupos de formação docente, aglutinados por interesses acadêmicos comuns;

- Oferecer a disciplina Didática do Ensino Superior, aos alunos dos programas de Pós-Graduação.

A implantação do FOPEPE abriu espaço para novas discussões sobre procedimentos e resultados das avaliações institucionais. Discussões que tiveram como metas o aprimoramento do processo avaliativo e o levantamento das características dos diferentes cursos, considerando o perfil dos docentes e discentes.

Por outro um ensino eficiente e eficaz requer uma reestruturação das práticas didático-pedagógicas, para que seja mantida a tradição, através de uma nova postura epistemológica educacional. Desse modo a educação estará contribuindo para a formação de profissionais competentes e eficazes com discernimento no trato da ciência e da tecnologia não apenas como instrumento de poder, mas sim de desenvolvimento humano.

Tem-se plena consciência da importância do papel de um educador consciente e prioriza-se a ênfase na avaliação formativa. Além disso, levase em conta a fala de Masetto $(1998 ; 2003)$ que entre outras ponderações relativas às mudanças no ensino superior, alerta sobre a superação da formação voltada apenas para o aspecto cognitivo;

o que se busca é que o aluno em seus cursos superiores esteja desenvolvendo competências e habilidades que se espera de um profissional capaz e de um cidadão responsável pelo desenvolvimento de sua comunidade. Isso fez com que os cronogramas curriculares se abrissem para atividades práticas integrando-se com teorias estudadas e a discussão de valores éticos, sociais, políticos, econômicos, por ocasião do estudo de problemas técnicos, integrando-se à análise teóricatécnica de determinada situação com os valores humanos e ambientais presentes e decorrentes da solução técnica apresentada. 
REFLEXÕES SOBRE O PROCESSO DE AVALIAR DOCENTE CONTRIBUINDO COM SUA FORMAÇÃO

Cabe, ao educador, passar conceitos e orientações, não de maneira repetitiva, como são encontrados nas brochuras e nos manuais, mas sim, a partir de segmentos reflexivos, de tal forma a fazer com que o aluno desenvolva um raciocínio lógico e progressivo. Para que tal fato ocorra, é necessário que o educador defina o plano do curso, apresente estratégias pedagógicas claras e que se utilize de recursos didáticos adequados ao desenvolvimento dos conteúdos.

Por outro lado, não há dúvidas que o professor deve ter domínio do conteúdo de sua disciplina. Segundo Vasconcelos (1994)

o domínio do conteúdo específico, acompanhado da constante atualização do mesmo, é cobrança facilmente identificável no discurso tanto institucional como discente. Não se admite um professor que não conheça o assunto que pretende ensinar. E essa é, também, uma preocupação marcadamente presente na fala do próprio professor.

Assim, deve haver preocupação específica com a capacitação e preparo do corpo docente. Ainda para Vasconcelos

A Universidade precisa conscientizar-se das necessidades de investir tempo, esforço e recursos em programas voltados para a capacitação e desenvolvimento de seus recursos humanos. Neste ponto, no entanto, devemos reafirmar uma vez mais que, se o que buscamos é a melhoria da qualidade do ensino universitário, não será apenas o profissional liberal-docente o único alvo a ser atingido pelas preocupações institucionais. Todos os docentes deverão constituir-se em preocupação semelhantes, igualmente válidas e necessárias. A universidade deve criar um espaço que possibilite as seus docentes a reflexão sobre sua própria prática, visando com isso, à melhoria da qualidade pedagógica de todos os seus cursos e de seus professores em exercício.

É importante que cada professor reflita com critérios sobre suas atividades e tente então redigir algo tecendo considerações sobre sua função.

Em busca de soluções sempre há de se inovar, no entanto, para Castanho (2000).

Não é fácil inovar. Muitas das novidades que encontramos sob a denominação de inovações podem ser versões recicladas e com novo rótulo de soluções tecnicistas, isto é, ligadas à racionalidade técnica 
existente. No entanto, há muito a mudar, muita coisa que pode parecer razoável, relevante e legítima. São coisas que parecem, muitas vezes, inamovíveis. O que as experiências parecem mostrar é que é relativamente fácil introduzir mudanças superficiais que não ameaçam as estruturas existentes. Desafiar e mudar as estruturas profundas do ensino constitui o grande desafio.

Veiga et al. (2000) apresentam algumas características dos docentes consideradas inovadoras nas atividades de ensino, pesquisa e aprendizagem: Instigam e propiciam as descobertas; trabalham com múltiplas tensões presentes na auto-atividade do aluno; favorece a relação horizontal, professor-aluno permitindo atendimento à singularidade de cada um e evitando a homogeneização; asseguram a relação ensino-aprendizagem com o trabalho como princípio educativo e atribuem à pesquisa importante espaço de mediação entre o ensinar e o aprender.

Monezi (1999) observa:

A Universidade e o meio acadêmico não podem se furtar ao chamamento que se lhes é imposto, e às graves responsabilidades de que são depositários como fórum competente que se constitui para o debate, a reflexão, a exposição de idéias e a consolidação de ideais.

A autora acrescenta ainda que é da Universidade que se espera maior desenvolvimento de know-how científico, tecnológico e humanístico rumo à superação dos obstáculos e desajustes que ainda assolam a sociedade na contemporaneidade.

O presente estudo não traz em seu escopo a pretensão de se imiscuir no delicado processo de avaliação dos docentes, mas por outro lado assevera, como de sua pertinência, destacar a requerida viabilização da educação continuada franqueada aos docentes, colocando-a como condição necessária para acompanhar a dinâmica imposta pela globalização e sobretudo para o exercício renovado e sempre vocacionado à qualidade do ensino. Neste particular, a Instituição deve fomentar todo o conjunto de ações destinadas à capacitação e "melhoria contínua" do seu corpo docente, através de cursos de atualização, seminários, congressos e toda a gama de eventos congêneres destinados ao mesmo propósito.

Levando em consideração os pressupostos teóricos e o resultado das avaliações apresenta-se o Curso de Capacitação Didática do Ensino Superior oferecidos aos professores que apresentaram avaliações insuficientes 
REFLEXÕES SOBRE O PROCESSO DE AVALIAR DOCENTE CONTRIBUINDO COM SUA FORMAÇÃO

nos aspectos didáticos oferecidos através do FOPEPE. Observa-se que o FOPEPE tem como preocupação constituir um grupo de professores para compor uma equipe que desenvolva abordagens adequadas em diferentes temáticas.

Este grupo, constituído por professores do $\mathrm{CCH}$ em sua maioria, realiza reuniões com o objetivo de refletir sobre a função social da universidade frente às exigências da sociedade contemporânea, bem como a articulação e inter-relação da teoria educacional e da prática pedagógica no ensino superior e o atendimento as orientações do SINAES.

O Curso abrange as questões relacionadas à docência do ensino superior: se aceita o desafio de rever seus paradigmas pessoais e profissionais dentro de uma proposta educacional integradora, voltada ao conjunto de conhecimentos, habilidades e atitudes necessárias para a formação integral de profissionais de sua área de trabalho, apresentadas as temáticas tratadas a seguir: 1-Profissão Professor; 2- Habilidades Didáticas do Professor Competente; 3- Dimensões do Processo Ensino-Aprendizagem: Relação Professor-Aluno; 4-Ação Pedagógica - Orientação para Elaboração de Plano de Ensino; 5-Avaliação Institucional e de Aprendizagem; 6Estratégias de Ensino e Aprendizagem; 7-Projetos Interdisciplinares no Ensino Superior; Elaboração do Plano de Ensino com Planejamento de Aulas; 8- Socialização dos Planos de Ensino. Fechamento das atividades desenvolvidas: avaliação conjunta dos encontros.

Os professores que participam do curso mostram interesse na elaboração de projetos pedagógicos, bem como nos planos de ensino das disciplinas. Nem todos os professores estão preparados para enfrentar as novas práticas docentes que se desenvolvem com a participação ativa do aluno, mas mostram um interesse grande em refletir e discutir metodologias diferenciadas buscando estratégias de ensino mais eficientes.

Os participantes percebem a importância e a necessidade de se pensar sistematicamente a docência do ensino superior, dada à relevância das temáticas apresentadas. Destacam-se as temáticas consideradas mais significativas: Elaboração do Plano de Ensino com Planejamento de Aulas, Estratégias de Ensino e Aprendizagem, Socialização dos Planos de Ensino e Ação Pedagógica - Orientação para Elaboração de Plano de Ensino.

Os professores deixam clara a preocupação em dividir suas angustias com seus pares e acreditam que discutindo os projetos dos cursos, se envolvendo em atividades extra classe e trocando experiências vão tornar sua prática diária mais agradável e eficaz. 
Configuram-se, assim, os compromissos pertinentes ao projeto político-pedagógico diferenciado, ao estabelecer a articulação entre a teoria educacional e a prática pedagógica; as intenções educativas decididas coletivamente com documento norteador de cada curso da universidade e o processo de construção e aperfeiçoamento contínuos.

O Professor é sem dúvida o ator principal do Ensino-Aprendizagem e a motivação passa a ser essencial para que as metas e objetivos educacionais sejam atingidos. Ele deve participar sempre, se envolver com os cursos oferecidos avaliando cada passo, contribuindo com suas idéias e concepções e tendo acesso a toda informação possível sobre a instituição na qual leciona.

Depois da análise dos resultados de avaliação do curso de Didática oferecido percebe-se claramente a carência de iniciativas para esclarecer alguns pontos nebulosos e para discutir projetos pedagógicos e planos de ensino.

Após refletir sobre aspectos tão significativos da educação profissional para a docência na universidade, pode-se inferir que nos dias de hoje, a universidade perdeu suas fronteiras espaciais e temporais, destacando-se o compromisso de todos com o social, o cultural e o comunitário. O papel da universidade é assim, de proporcionar condições para que os educadores/professores sintam-se envolvidos como sujeitos éticos do processo, que entusiasmados, tenham vontade de sonhar, e que comprometidos, percebam a articulação e a indissociabilidade do ensino-pesquisa-extensão, com oportunidades para criar, fazer acontecer.

No entanto, o ato de avaliar deve ser contínuo, pois o caminho rumo a excelência é uma estrada sem fim e a qualidade esperada se torna cada vez maior. Como bem assinala Masetto (2004),

Numa avaliação institucional, há de se compreender a instituição educacional como uma totalidade integrada, de modo que os dados informativos dos diferentes setores só ganham vida e sentido quando analisados comparativamente. Em outras palavras, os dados levantados em cada um dos setores são relativos e exigem um processo de integração entre si, pois, se justapostos, sem uma leitura integrada, não permitirão um diagnóstico correto da situação global nem a indicação de propostas adequadas. A avaliação de setores independentes uns dos outros não é uma fonte adequada para diagnósticos, conclusões e encaminhamentos para a melhoria da instituição. 
REFLEXÕES SOBRE O PROCESSO DE AVALIAR DOCENTE CONTRIBUINDO COM SUA FORMAÇÃO

A busca da melhoria é uma tarefa permanente e contínua. Para que a qualidade seja priorizada continuamente, é necessário manter os processos e buscar soluções. Em 2004 e 2005 forma novamente realizadas avaliações docentes o processo de avaliação docente em 2004 e 2005 tem-se os resultados com os seguintes resultados:

Tabela 2-Resultados (médias) obtidos nos cursos de Engenharia, Comunicação e Artes e Arquitetura em 2004/2005.

\begin{tabular}{|l|c|c|}
\hline Unidade & $\mathbf{2 0 0 2}$ & $\mathbf{2 0 0 3}$ \\
\hline Engenharia & & 3,98 \\
\hline Arquitetura & 3,58 & 3,93 \\
\hline Comunicação e Artes & 3,87 & 3,97 \\
\hline
\end{tabular}

A Avaliação Institucional deve, portanto, organizar os diversos instrumentos avaliativos de acordo com o princípio da integração.

Os resultados apresentaram, na média, uma discreta melhoria. Agora, 92\% dos alunos consideram que seus professores conhecem muito bem o conteúdo que desenvolve, não tem a didática necessária (30\%), não se utilizando de metodologias outras que não a aula expositiva (29\%).

Os dados apontam para a eficiência dos cursos de Didática, pois as questões sobre a didática e a metodologia e ensino foram mais bem avaliadas. No primeiro momento $38 \%$ gostariam de cursar novamente uma disciplina, depois dos encontros de Didática $47 \%$ gostariam de fazê-lo.

$\mathrm{O}$ ensino superior é um dos maiores desafios da atualidade. Para Masson (2005)

o ponto crucial é eficiência do aprendizado, porque o mundo atual é muito dinâmico, e as mudanças ocorrem rapidamente. Assim, a eficiência deve garantir a qualidade do ensino e para tanto a avaliação na sua forma mais abrangente é absolutamente necessária, pois possibilita inclusive o desenvolvimento de mecanismos de informações que permitam a identificação dos problemas situacionais.

A atuação Docente da Instituição apresentou melhora significativa, no entanto é certo que a Educação Continuada é imprescindível para man- 
ter o profissional atualizado. Para isso a oferta de cursos, palestras e outros eventos deverá ser contínua, com temáticas diferenciadas buscando abranger o maior número possível de profissionais.

Só avaliar não é suficiente, Para Dias Sobrinho (2003),

A avaliação não é um processo auto limitado que basta a si mesmo. Visando tornar mais visível e compreensível o cotidiano de uma instituição, a avaliação ultrapassa amplamente os âmbitos mais restritos do objeto a avaliar e lança seus efeitos sobre o sistema de educação superior e suas funções relativamente à construção da sociedade. Ela ilumina e instrumentaliza as reformas educacionais, desde a mudança nos currículos, maneiras de organização dos cursos e formas gerenciais, até novas estruturas do sistema.

É preciso buscar soluções objetivas que A avaliação não pode ser reduzida a um único processo. Dever ser contínua e permanente. Isenta de um pré-julgamento, deve contribuir para que as mudanças ocorram, tendo como meta a melhoria constante do ensino-aprendizagem.

\section{Considerações finais}

A auto-avaliação institucional deve ter um caráter educativo, de melhora constante e de auto regulação. Quanto mais ampla e dedicada a participação dos envolvidos mais resultados positivos surgirão e maior será a eficiência dos processos pedagógicos desenvolvidos. Para Monezzi (2003), como resultado desta iniciativa promovida pela universidade quanto ao incentivo ao desenvolvimento profissional, manifestam-se os compromissos científicos (princípios, fatos, conceitos) e filosóficos (valores, atitudes e normas) do professor para resolução de conflitos, e indicação de caminhos para que um processo dialético de construção do conhecimento seja evidenciado para o enfrentamento dos desafios educacionais e comunitários.

Entende-se também não ser o processo de avaliação algo que se possa finalizar. É necessário ajustes, mudanças e alterações para acompanhar o desenvolvimento dos cursos e das áreas de conhecimento. O levantamento de dados e a sua organização são aspectos importantes no processo de avaliação, mas deve-se ter consciência que avaliar não se resume a isso. Avaliar não é simplesmente medir. Avaliar não é um processo isolado. A 
REFLEXÕES SOBRE O PROCESSO DE AVALIAR

DOCENTE CONTRIBUINDO COM SUA FORMAÇÃO

avaliação deve ser a grande motivadora de questionamentos sobre juízo de valores, tendo em vista a formação integral dos estudantes.

Propõe-se uma síntese do que é necessário discutir e refletir sobre o que se espera do professor frente às novas concepções de avaliação e ensino:

- organização curricular mais flexível, com mecanismos automáticos de atualização e oferta de disciplinas optativas de caráter interdisciplinar;

- A interdisciplinaridade deve ganhar espaço, permitindo a realização de trabalhos científicos. Na verdade, o modelo vigente de arranjo curricular, em que as disciplinas básicas estão concentradas nos semestres iniciais dos cursos, precisa ser reavaliado. A introdução de disciplinas práticas, desde o início, pode ajudar a motivação do aluno;

- incentivo à criatividade, sempre acompanhado do domínio do conhecimento específico que leve o aluno à resolução de problemas reais;

- materiais modernos de aprendizagem que estimulem e realmente motivem o aluno em espaço adequado e agradável;

- criação de oportunidades de educação continuada aos docentes, estímulos de realização de cursos de atualização e participação em congressos, valorizando atividades acadêmicas e as voltadas para a profissionalização.

\section{REFERENCIAS}

ANASTASIOU, Lea Graças Camargos; ALVES, Leonir Pessate. (Orgs.). Processos de ensinagem na universidade: pressupostos para as estratégias de trabalho em aula. Joinville, SC: UNIVILLE, 2003.

CASTANHEIRA, A. M. P.et al. Avaliação e formação de docentes sob a ótica do SINAES. In: CONGRESSO BRASILEIRO DO ENSINO DE ENGENHARIA, 33, 2005, Campina Grande, PB. Anais eletrônicos. Campina Grande, PB: [s.n.], 2005.

CASTANHO, Maria Eugenia L. M. Professores e inovações In: CASTANHO, Sergio; CASTANHO, Maria Eugenia E. L. (Orgs.). O que há de novo na Educação Superior: do projeto pedagógico à prática transformadora. Campinas, SP: Papirus, 2000. 
COMISSÃO NACIONAL DA EDUCAÇÃO SUPERIOR - CONAES / INSTITUTO NACIONAL DE ESTUDOS E PESQUISAS EDUCACIONAIS ANÍSIO TEIXEIRA - INEP. Avaliação externa de instituições de educação superior: diretrizes e instrumentos. Brasília, DF: MEC, nov. 2005.

DIAS SOBRINHO, Jose. Políticas educacionais e reformas da educação superior. São Paulo: Cortez, 2003.

HOFFMANN, J. Avaliação mediadora: uma prática em construção da préescola 'a universidade. 20. ed. Porto Alegre: Mediação, 2003.

LEAL, Maria Gloria. Currículo baseado em competências: uma proposta para os cursos de graduação em Engenharia". In: WORLD CONGRESS ON ENGINEERING AND TECHNOLOGY EDUCATION, 1, 2004, Guarujá, SP. Anais eletrônicos. Guarujá, SP: [s. n.], 2004.

LIBÂNEO, J.C. et al. Educação escolar: políticas, estrutura e organização. São Paulo: Cortez, 2003.

LUCKESI, C.C. Avaliação da aprendizagem escolar: estudos e proposições. 14. ed.

São Paulo: Cortez, 2002.

MACHADO, Nilson José. Ensaios transversais: cidadania e educação. São Paulo: Escrituras, 1997.

MASSON, T. J . et al. Eficiência e eficácia no ensino de engenharia! In: CONGRESSO BRASILEIRO DO ENSINO DE ENGENHARIA, 33, 2005, Campina Grande, PB: Anais eletrônicos. Campina Grande, PB: [s. n.], 2005.

MASETTO, Marcos T. Competência pedagógica do professor universitário. São Paulo: Summus, 2003.

Professor universitário: um profissional da educação na atividade docente. In: MASETTO, Marcos T. (Org.). Docência na universidade. São Paulo: Papirus, 1998.

MONEZI, M. R. Ceroni. Qualificação profissional: atualização curricular do Curso de Administração de Empresas em uma faculdade particular da cidade de São Paulo. 1999. Tese (Doutorado) - Universidade Presbiteriana Mackenzie, São Paulo, 1999.

MONEZI, M. R. C., RIBEIRO, M. C. C. M., LAGUNA, A..J. Paradigmas contemporâneos da gestão educacional: uma visão inclusiva. Revista de Cultura do IMAE, São Paulo, n. 11, ano 5, p.54-62, 2004. 
REFLEXÕES SOBRE O PROCESSO DE AVALIAR

DOCENTE CONTRIBUINDO COM SUA FORMAÇÃO

MORAES, Sílvia. Currículo, transversalidade e pós-Modernidade. In: SANTOS FILHO, Camilo; MORAES, Silvia (Org.). Escola e universidade na pós modernidade. Campinas, SP: Mercado de Letras; Fapesp, 2000. p. 201247.

SILVA, M. P.; LEAL, M. G. Currículo baseado em competências: uma proposta para os cursos de graduação em Engenharia. In: WORLD CONGRESS ON ENGINEERING AND TECHNOLOGY EDUCATITION, 1 Guarujá, SP: Anais eletrônicos, Guarujá, SP: [s. n.], 2004.

RISTOFF, Dilvo. Avaliação Institucional: pensando princípios. In: BALZAN, N. C.; DIAS SOBRINHO, J. (Orgs). Avaliação institucional: teoria e experiências. São Paulo: Cortez, 1995.

SISTEMA NACIONAL DE AVALIAÇÃO DA EDUCAÇÃO SUPERIOR SINAES. Da concepção à regulamentação. Brasília: INEP, 2004.

VASCONCELOS, M.L. M. O profissional liberal na docência de terceiro grau: uma proposta de Atualização Pedagógica. 1994. Tese (Doutorado em Administração) - Universidade Presbiteriana Mackenzie, São Paulo, 1994.

VEIGA, Ilma Passos Alencar. Projeto político-pedagógico: continuidade ou transgressão para acertar?. In: CASTANHO, Sergio.; CASTANHO, Maria.Eugenia (Orgs.). O que há de novo na educação superior: do projeto pedagógico à prática transformadora. Campinas, SP: Papirus, 2000. 